\title{
Diversity of reef associated fishes in hook and line fishery at Mandapam, Gulf of Mannar, south-east coast of India
}

\author{
MOLLY VARGHESE AND A. GANDHI \\ ICAR-Central Marine Fisheries Research Institute, Kochi - 682 018, Kerala, India \\ "Mandapam Regional Centre of ICAR-Central Marine Fisheries Research Institute, Mandapam - 623520 \\ Tamil Nadu, India \\ e-mail: mollykandathil@hotmail.com
}

\section{ABSTRACT}

Reef associated fishes landed by hooks and lines at Mandapam landing centre in Ramanathapuram District, Tamil Nadu for a period of four years from October 2008 to May 2012 were studied based on fortnightly samplings. The hook and line fishing is seasonal in Gulf of Mannar and lasts for six months annually from October - November to April - May, as this area remains rough during the rest of the year. The average annual landing of fish during the study period was $171 \mathrm{t}$ with a peak of $295 \mathrm{t}$ in 2008-09 and showed a decline since then. A total of 32 species of reef associated fishes belonging to 14 families were landed. Among them, Sphyraena barracuda contributed the maximum with a share of $42 \%$ followed by Caranx heberi $(15 \%)$. Family-wise landings indicated the dominance of Sphyraenidae (46\%). The diversity index (H') was the highest during 2008-09 and the evenness of distribution of individuals among different species did not show significant variation in different years. Funnel plots of average taxonomic distinctness $\left(\Delta^{+}\right)$and variation in taxonomic distinctness $\left(\lambda^{+}\right)$indicated that the values in most of the years are within the normal limits.

Keywords: Diversity, Gulf of Mannar, Hook and line, Reef associated fishes, South-east India

\section{Introduction}

The coral reef ecosystem of Gulf of Mannar supports a wide spectrum of flora and fauna of taxonomic and economic importance. Among the fauna, finfishes form a dominant component and different types of fishing methods are practiced in this ecosystem including fishing using hooks and lines. The hook and line fishery off Mandapam is seasonal and takes place from OctoberNovember to April-May as the Gulf of Mannar remains rough during the other months. Even though some studies have been carried out on hook and line fishery in southeast coast of India (Menon et al., 1993; Durai et al., 2011; Radhakrishnan et al., 2016), a systematic study on this fishery on reef associated fishes alone from Mandapam was not reported earlier. Hence, an attempt was made to study the diversity of reef associated fishes landed by hooks and lines at Mandapam from the Gulf of Mannar.

\section{Materials and methods}

Fortnightly samples and fish landing data were collected from Mandapam fish landing centre $\left(79^{\circ} 8^{\prime} \mathrm{N}\right.$; $9^{\circ} 15^{\prime}$ E) landed by hooks and lines from Gulf of Mannar (GOM), for a period of four years from October, 2008 to May, 2012. The area of the GOM under the Indian EEZ is about 15000 sq. km, where commercial fishing takes place in about 5500 sq. km (Nammalwar and Edwin Joseph,
2002). The fishes landed were identified up to species level as per Fischer and Bianchi (1984), Smith and Heemstra (1986) and Munro (2000). The weight as well as numbers of each species landed were estimated. From the total landings, the data pertaining to reef associated fishes alone was separated, as fishes other than reef associated fishes are also landed here by hooks and lines. Specieswise, family-wise, month-wise and year-wise catch data of reef associated fishes were generated and analysed using PRIMER (v.6) software (Clarke and Gorley, 2006). Conventional diversity indices like Shannon diversity index (H' log e), Margalef's richness index (d), Pielous evenness index (J') and Simpson index (1-Lambda') were derived to understand the fish diversity in different years. To compare the diversity between the years, dominance plot was drawn. The data were fourth root transformed before the computation of diversity indices, similarity and cluster analysis. The similarity in species composition was studied by calculating the Bray-Curtis coefficient and similarity matrices were constructed. In the cluster analysis, the hierarchical agglomerative clustering, Bray-Curtis similarity was used to construct the map. Diversity indices like taxonomic diversity index $(\Delta)$, average taxonomic distinctness index $\left(\Delta^{+}\right)$and variation in taxonomic distinctness $\left(\lambda^{+}\right)$were used to compare diversity between different years (Clarke and Warwick, 
2001). Deviation from the normal distribution and variance between the samples were tested by plotting $95 \%$ funnel plots using $\Delta^{+}$and $\lambda^{+}$values.

\section{Results and discussion}

Qualitative and quantitative abundance

The hook and line fishery at Mandapam indicated that $50 \%$ by weight of the fishes landed were reef associated fishes. A total of 32 species of reef associated fishes belonging to 17 genera under 14 families were recorded during the study period (Table 1).

Molly Varghese et al. (2017) recorded 98 species of reef fishes from trap fishery at Keelakarai while Molly Varghese and Joshi (2017) reported 69 species from bottom-set gillnet landings at Pamban from Gulf of Mannar. Thus, the number of species recorded was found to vary with type of gear and comparatively lower number of species was recorded in hook and line landings during the present study. Venkataramani (2011) also observed the lowest number of fishes in hook and line landings from Gulf of Mannar. Along with species number, the species composition also was found to differ with fishing gear. Species-wise dominance (\%) among total reef associated fishes landed during the present study is depicted in Fig. 1 (species which contributed less than 1\% are not included in the figure).

Species composition indicated the dominance of Sphyraena barracuda (42\%) followed by Caranx heberi (15\%), Scomberoides tol (13\%), Lethrinus nebulosus (9\%) and rest of the species contributed less than 5\% each. A study conducted by Jayasankar (1990) at Pamban, near Mandapam revealed the dominance of Lethrinus spp. and Lutjanus spp. in total landings by hook and line fishery. During his study, plank-built boats were used for operating hook and line at a depth of $18-25 \mathrm{~m}$, while during the

Table 1. List of reef associated fishes landed by hook and line at Mandapam during the study period

\begin{tabular}{|c|c|c|}
\hline Species & Family & Common name \\
\hline Acanthurus gahhm & Acanthuridae & Black surgeonfish \\
\hline Strongylura leiura & Belonidae & Banded needlefish \\
\hline Caranx heberi & Carangidae & Blacktip trevally \\
\hline Megalaspis cordyla & Carangidae & Torpedo scad \\
\hline Scomberoides commersonnianus & Carangidae & Talang queenfish \\
\hline S. tala & Carangidae & Barred queenfish \\
\hline S. tol & Carangidae & Needlescaled queenfish \\
\hline Chirocentrus dorab & Chirocentridae & Dorab wolf-herring \\
\hline Amblygaster sirm & Clupeidae & Spotted sardinella \\
\hline Ephippus orbis & Ephippidae & Orbfish \\
\hline Platax teira & Ephippidae & Longfin batfish \\
\hline Plectorhinchus diagrammus & Haemulidae & Striped sweetlips \\
\hline Plectorhinchus pictus & Haemulidae & Trout sweetlips \\
\hline Pomadasys maculatus & Haemulidae & Saddle grunt \\
\hline Lethrinus miniatus & Lethrinidae & Trumpet emperor \\
\hline L. nebulosus & Lethrinidae & Spangled emperor \\
\hline L. ornatus & Lethrinidae & Ornate emperor \\
\hline Lutjanus bohar & Lutjanidae & Two-spot red snapper \\
\hline L. fulviflamma & Lutjanidae & Dory snapper \\
\hline L. gibbus & Lutjanidae & Humpback red snapper \\
\hline L. lutjanus & Lutjanidae & Bigeye snapper \\
\hline L. russellii & Lutjanidae & Russell's snapper \\
\hline Gymnothorax favagineus & Muraenidae & Laced moray \\
\hline G. punctatus & Muraenidae & Red Sea whitespotted moray \\
\hline Rachycentron canadum & Rachycentridae & Cobia \\
\hline Scarus ghobban & Scaridae & Blue-barred parrotfish \\
\hline Epinephelus malabaricus & Serranidae & Malabar grouper \\
\hline E. merra & Serranidae & Honeycomb grouper \\
\hline E. tauvina & Serranidae & Greasy grouper \\
\hline E. bleekeri & Serranidae & Duskytail grouper \\
\hline Sphyraena barracuda & Sphyraenidae & Great barracuda \\
\hline S. jello & Sphyraenidae & Pickhandle barracuda \\
\hline
\end{tabular}




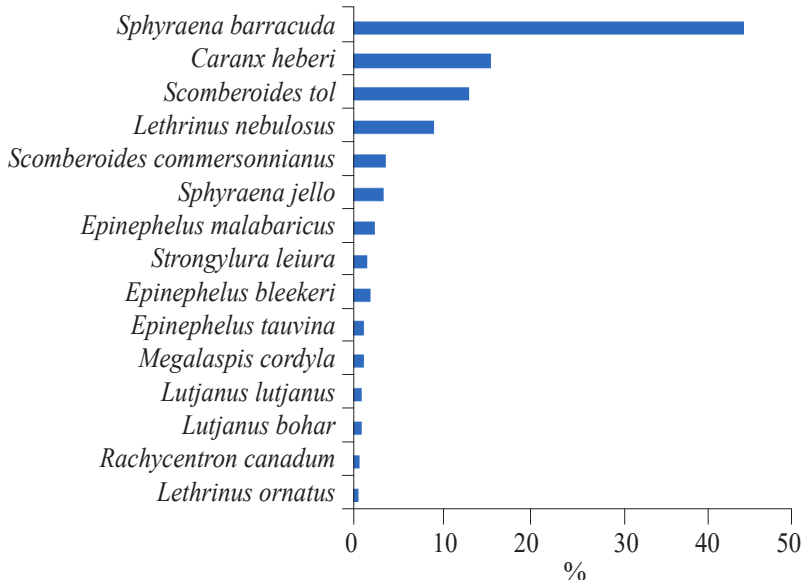

Fig. 1. Species composition of reef associated fishes at Mandapam during 2008-2012

present study, fibre glass boats operated the gear at a depth of 24-84 m and this change in craft and depth of operation along with the period of study could be the reason for the difference in catch composition. An unusual hook and line fishery of $S$. barracuda was recorded along Cuddalore coast of Tamil Nadu during January 2009 (CMFRI, 2009) which coincides with the period of the present study. Lal Mohan and Nandakumaran (1988) studied the hand line fishing along Malabar coast during October - January and observed the dominance of Sphyraena spp. and Rachycentron canadum wherein the gear was operated along the rocky beds about $12-15 \mathrm{~km}$ away from the shore at a depth of 20-30 m using catamaran. These findings indicate that the species composition differ with locality, gear and craft, type of ecosystem, depth of operation and period of study.

Family-wise quantitative abundance of reef associated fishes landed at Mandapam by the hook and line fishery is illustrated in Fig. 2. Among the 14 families, Sphyraenidae

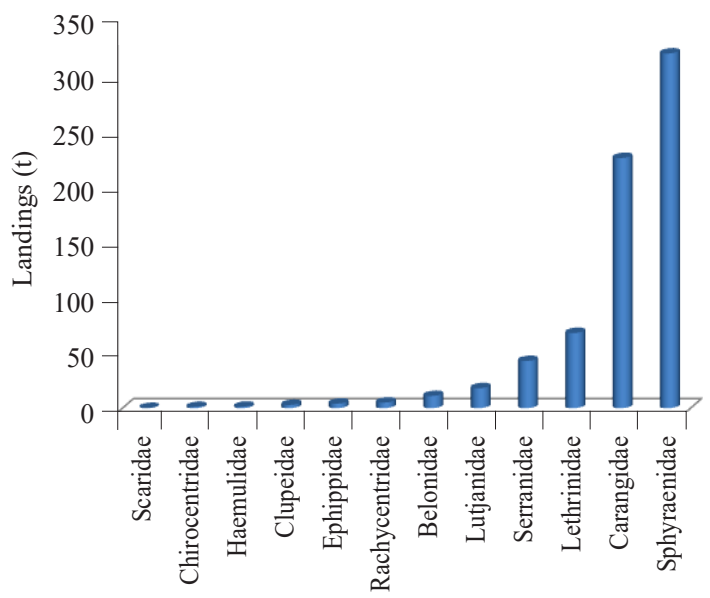

Fig. 2. Family-wise reef associated fish landings during the study period formed the maximum with a share of $46 \%$ followed by Carangidae (32\%), Lethrinidae (10\%), Serranidae (6\%) and the rest of the families contributed less than $4 \%$. While studying the hook and line fishery in Kombuthurai coast, Tamil Nadu, Radhakrishnan et al. (2016) observed major contributions by food fishes in handline fishery, as needle fish (33\%), barracuda (32\%), carangids (22\%) and groupers $(13 \%)$ dominated. This finding is in agreement with the present study except in the case of needle fishes, which may be due to the difference in the locality and period of the study.

Year-wise landings indicated an average of $171 \mathrm{t}$ per year during the study period with a maximum of $295 \mathrm{t}$ during 2008-09. Afterwards it showed a decline during the rest of the study period (Fig. 3). A similar trend in landings by traps at Keelakarai was also recorded by Molly Varghese et al. (2017).

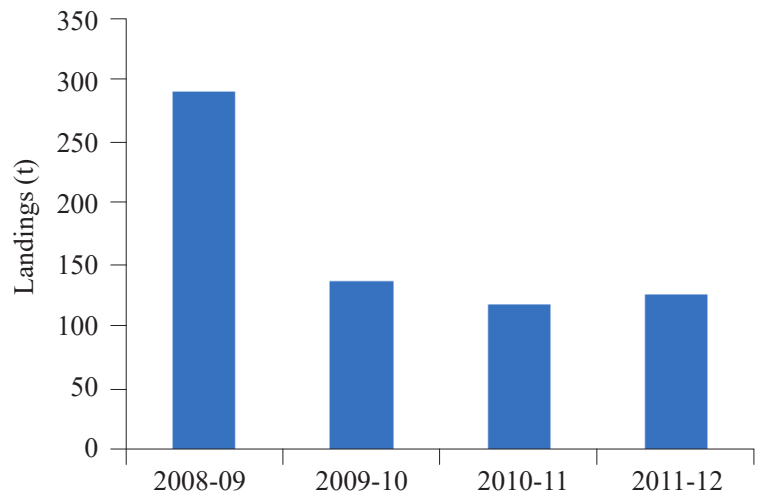

Fig. 3. Year-wise landings of reef associated fishes during the study period

\section{Diversity indices}

The diversity indices along with some attributes of community structure of reef associated fishes in different years are given in Table 2. The Shannon-Wiener's diversity index (H') which is the most commonly used diversity measure showed slightly higher value during 2008-09 which indicate that species composition was slightly different in this year than the rest of the years. The Margalef's Richness index (d) which incorporates the number of individuals $(\mathrm{N})$ and species number $(\mathrm{S})$ also showed higher value during 2008-09. The equitability or Evenness index (J') which expresses the evenness of distribution of individuals among the different species did not show much variation and the values ranged from 0.94 to 0.98 .

In the dominance plot, the curve for 2008-09, which lies on the lower side, extends further and rises slowly due to the presence of more number of species when 
Table 2. Diversity indices and taxonomic attributes of reef associated fishes landed by hooks and lines at Mandapam during 2008-2012

\begin{tabular}{llllllllll}
\hline Year & $\mathrm{S}$ & $\mathrm{N}$ & $\mathrm{d}$ & $\mathrm{J}$ & H'(loge) & 1-Lambda' & Delta & Delta + & Lambda + \\
\hline $2008-09$ & 25 & 183.86 & 4.60 & 0.94 & 3.04 & 0.95 & 48.20 & 51.56 & 132.77 \\
$2009-10$ & 17 & 130.39 & 3.29 & 0.98 & 2.77 & 0.94 & 43.73 & 46.32 & 104.95 \\
$2010-11$ & 18 & 120.38 & 3.55 & 0.95 & 2.74 & 0.93 & 48.16 & 50.65 & 144.82 \\
$2011-12$ & 21 & 155.79 & 3.96 & 0.97 & 2.94 & 0.95 & 47.61 & 51.03 & 116.66 \\
\hline
\end{tabular}

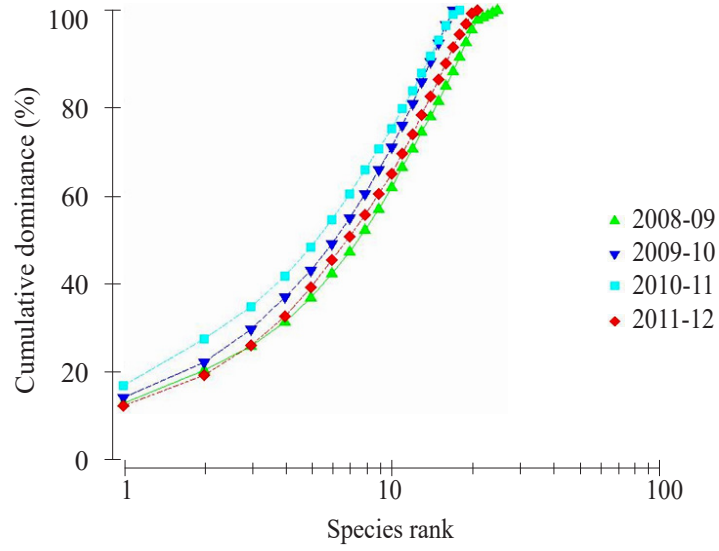

Fig. 4. Dominance plot of reef associated fishes landed at Mandapam during the study period

compared to rest of the years (Fig. 4). Since the percentage contribution of each species is added, the curve extends horizontally along with species numbers in the X-axis before reaching the cumulative $100 \%$.

The similarity in species composition and abundance among different years as derived from Bray-Curtis similarity matrix indicated that the maximum similarity of $75 \%$ was between $2009-10$ and 2011-12 and the similarity was found to be minimum (65\%) between 2009-10 and

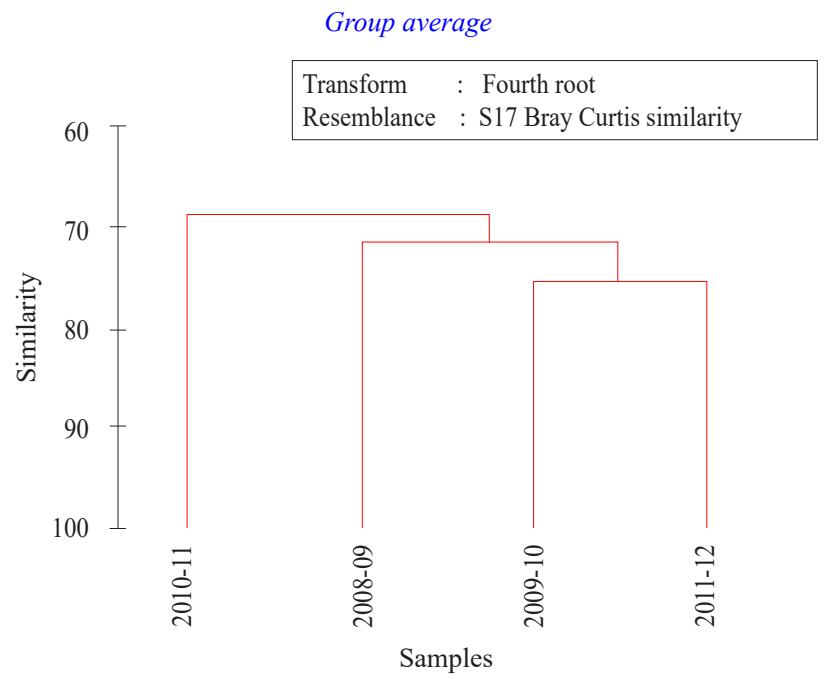

Fig. 5. Dendrogram of reef associated fishes landed at Mandapam during 2008-2012
2010-11. The dendrogram (Fig. 5) revealed separate grouping based on similarity in species composition and abundance of different years. The years 2009-10 and 2011-12 formed a group with the maximum similarity percentage of 75 and other years got linked to them at different levels of similarity percentages.

The degree to which species in a sample are taxonomically related to each other can be measured using the average taxonomic distinctness $\left(\Delta^{+}\right)$and variation in taxonomic distinctness $\left(\lambda^{+}\right)$. The average taxonomic distinctness was found to be the minimum during 2009-10 and maximum during 2008-09 (Table 2). This indicates that more closely related species are available during 2009-10 while the taxonomic distance between species was the highest during 2008-09.

In the funnel plot of $\Delta^{+}$against number of species (Fig. 6), only 2009-10 falls outside the confidence funnel but very near to the funnel and majority of the points are within the normal limits which indicate that the taxonomic distinctness between the years is not statistically significant.

The variation in taxonomic distinctness $\left(\lambda^{+}\right)$ranged between 104.95 in 2009-10 and 144.82 in 2010-11 which indicates the wide range in taxonomic distances between pairs of species in different years (Fig. 7). Hence, the

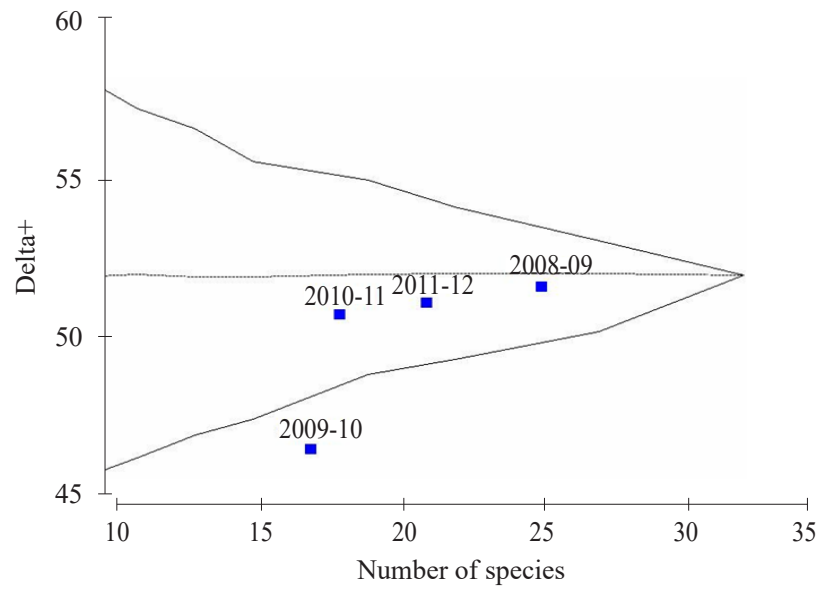

Fig. 6. Funnel plot for average taxonomic distinctness $\left(\Delta^{+}\right)$ showing the diversity of reef associated fishes landed at Mandapam in different years and its deviation from the normal distribution 


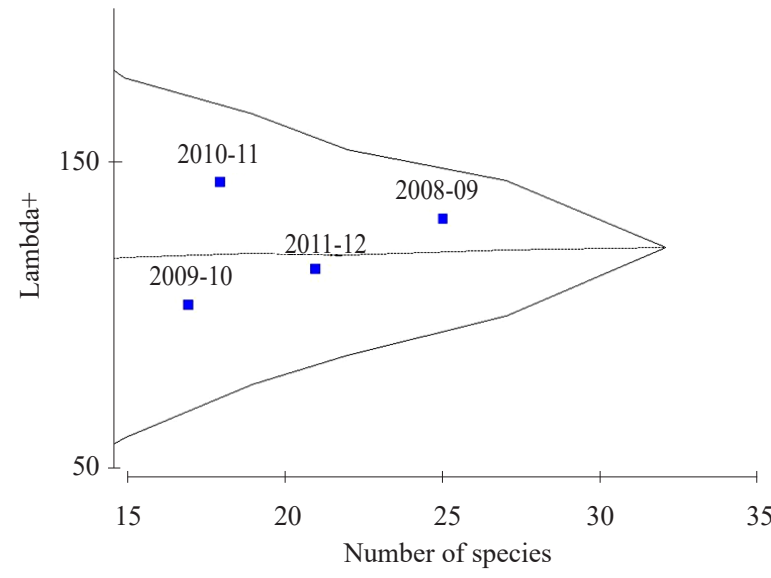

Fig. 7. Funnel plot for variation in taxonomic distinctness $\left(\lambda^{+}\right)$of reef associated fishes landed at Mandapam in different years during the study

unevenness of the taxonomic tree structure was greater during 2010-11 when compared to that of other three years. As all the values of $\lambda^{+}$lies inside the funnel plot, it is considered that they are within the normal limits. The annual fish landings were also found to be almost the same during the study period. Thus, it is assumed that the hook and line fishery at Mandapam is steady at present and regular monitoring is necessary for the sustenance of the fishery.

\section{Acknowledgements}

The authors are thankful to the Director, ICARCMFRI, Kochi; Dr. K. K. Joshi and to Dr. G. Gopakumar for providing facilities and encouragements. They are also grateful to Shri. V. J. Thomas, Smt. P. M. Geetha, Shri. K. M. Sreekumar and Shri. M. Seeni for the help rendered during the study.

\section{References}

Clarke, K. R. and Gorley, R. N. 2006. PRIMER v6. user manual, $1^{\text {st }}$ edn. PRIMER-E Ltd., Plymouth, UK.

Clarke, K. R. and Warwick, R. M. 2001. Changes in marine communities: An approach to statistical analysis and interpretation, $2^{\text {nd }}$ edn., PRIMER-E Ltd., Plymouth, $112 \mathrm{pp}$.

CMFRI 2009. Unusual hooks and line fishery of Sphyraena barracuda along Cuddalore coast. CMFRI Newsletter, 120: $15 \mathrm{pp}$.
Durai, V., Neethiselvan, N., Chrisolite, B. and Sundaramoorthy, B. 2011. Longline selectivity and fishing pressure on the fishery of Lethrinus elongatus off Thoothukudi coast. Tamil Nadu J. Vet. Anim. Sci., 7(3): 137-143.

Fischer, W. and Bianchi, G. 1984. FAO Species identification sheets for fishery purposes. Western Indian Ocean (Fishing Area 51), vol. 4. Food and Agriculture Organisation of the United Nations, Rome.

Jayasankar, P. 1990. On the seasonal hooks and line fishery at Pamban, near Mandapam. Mar. Fish. Infor. Serv. $T \& E$ Ser., 105: 13-14.

Lal Mohan, R. S. and Nandakumaran, K. 1988. On a seasonal hooks and line fishery with catamarans along Calicut coast. Mar. Fish. Infor. Serv. T\& E Ser., 83: 23-25.

Menon, N. G., Bensam, P. and Balachandran, K. 1993. Hooks and line fishery resources of India. In: Proceedings of the National workshop on low energy fishing. 8-9 August 1991, Society of Fisheries Technologists (India), ICAR-Central Institute of Fisheries Technology, Kochi, India, p. 30-38.

Molly Varghese and Joshi, K. K. 2017. Reef fish diversity of bottom set gillnet landings at Pamban, Tamil Nadu, India J. Mar. Biol. Ass. India, 59(1): 14-18. doi: 10.6024/jmbai. 2017.59.1.1958-02.

Molly Varghese, Ranjith L. and Joshi K. K. 2017. Diversity of reef fishes in trap fishery at Keelakarai, Gulf of Mannar, south-east coast of India. Indian J. Fish., 64(1): 23-30. DOI: 10.21077/ijf.2017.64.1.53263-04.

Munro, I. S. R. 2000. The marine and freshwater fishes of Ceylon, Narendra Publishing House, New Delhi, India, 352 pp.

Nammalwar, P. and Edwin Joseph, V. 2002. Bibliography of the Gulf of Mannar, CMFRI Special Publication No. 74. Central Marine Fisheries Research Institute, Kochi, India, 204 pp.

Radhakrishnan, K., Kalaiarasan, M., Madan, M. S., Ananth, P. N., Umamaheswari, T. and Velmurugan, R. 2016. Economic analysis of the hook and line fishery in Kombuthurai coast, Tamil Nadu. Current World Environment, 11(3): 926 -933. doi.org/10.12944/CWE.11.3.28.

Smith, M. M. and Heemstra, P. C. 1986. Smith's sea fishes. Springer - Verlag, Berlin, 1048 pp.

Venkataramani, V. K. 2011. Fisheries resources and practices in the Gulf of Mannar. GOMBRT Publication, 19: 173-202.

Date of Receipt $\quad$ : 14.08 .2018

Date of Acceptance : 25.04 .2019 